\title{
A randomized controlled trial of lifestyle self-monitoring for irritable bowel syndrome in female nursing school students
}

\author{
Yukiko Okami ${ }^{1,2 *}$, Gyozen Nin', Kiyomi Harada ${ }^{2,3}$, Masayo Iwasa ${ }^{4}$, Kaori Kitaoka ${ }^{2,5}$, \\ Susumu Takakuwa ${ }^{8}$, Motoyori Kanazawa ${ }^{9}$, Shin Fukudo ${ }^{9}$, Tomiko Tsuji ${ }^{1}$, Akane Higashi ${ }^{4}$ \\ ${ }^{1}$ Department of Health and Nutrition, Nagoya Bunri University, Inazawa, Japan \\ ${ }^{2}$ Ex-Graduate School of Life and Environmental Sciences, Kyoto Prefectural University, Kyoto, Japan \\ ${ }^{3}$ School of Nursing, Kyoto Prefectural University of Medicine, Kyoto, Japan \\ ${ }^{4}$ Graduate School of Life and Environmental Sciences, Kyoto Prefectural University, Kyoto, Japan \\ ${ }^{5}$ Department of Health and Nutrition, Kyoto Koka Women's University, Kyoto, Japan \\ ${ }^{6}$ Faculty of Bioenvironmental Science, Kyoto Gakuen University, Kameoka, Japan \\ ${ }^{7}$ Department of Gastroenterology, Japan Red Cross Kyoto Daiichi Hospital, Kyoto, Japan \\ ${ }^{8}$ Department of Education, Kyoto Women's University, Kyoto, Japan \\ ${ }^{9}$ Department of Behavioral Medicine, Tohoku University Graduate School of Medicine, Sendai, Japan \\ Email: "okami.yukiko@nagoya-bunri.ac.jp
} Ayako Saruwatari ${ }^{4}$, Wataru $\mathrm{Aoi}^{4}$, Sayori $\mathrm{Wada}^{4}$, Misaka Kimura ${ }^{6}$, Hiroaki Asano ${ }^{3}$, Yusuke Okuyama ${ }^{7}$,

Received 1 November 2013; revised 5 December 2013; accepted 16 December 2013

Copyright (c) 2013 Yukiko Okami et al. This is an open access article distributed under the Creative Commons Attribution License, which permits unrestricted use, distribution, and reproduction in any medium, provided the original work is properly cited. In accordance of the Creative Commons Attribution License all Copyrights (c) 2013 are reserved for SCIRP and the owner of the intellectual property Yukiko Okami et al. All Copyright (c) 2013 are guarded by law and by SCIRP as a guardian.

\begin{abstract}
Background: The aim of this study was to verify the efficacy of lifestyle self-monitoring for the improvement of the IBS and reveal what has been changed due to the intervention. Methods: A total of 111 nursing school students were randomized into three groups, two intervention groups (a two-month intervention group, $\mathbf{n}=34$, and a four-month intervention group, $n=35)$ and a control group $(n=34)$. The intervention groups conducted lifestyle self-monitoring in conjunction with a 15-minutes group work for either two or four months. The primary outcome measure was Rome II criteria for IBS. Other outcome measures were the Hospital Anxiety and Depression Scale (HADS) and the Gastrointestinal Symptom Rating Scale (GSRS). They were assessed at the baseline and the end of both of the intervention periods. Analysis was conducted as intention-to-treat. Results: The prevalence of IBS did not change significantly after the intervention in any of the groups. The HAD-A score, a subscale of the HADS score for anxiety, decreased 1.4 points in the two-month intervention group $(p=$ 0.02 ) and 2.3 points in the four-month intervention group of $(p=0.01)$ after intervention. The average

\footnotetext{
"Corresponding author.
}

GSRS decreased 0.2 points in the control group ( $p=$ 0.05 ) and 0.3 points in the four-month intervention group $(p<0.01)$. Conclusions: Lifestyle self-monitoring for two or four months did not reduce the prevalence of the IBS significantly, but it did decrease anxiety and improved the QOL related to gastrointestinal symptoms in female nursing school students.

Keywords: Lifestyle; Self-Monitoring; Irritable Bowel Syndrome; Hospital Anxiety and Depression Scale; Gastrointestinal Symptom Rating Scale; Nursing School

\section{INTRODUCTION}

Irritable bowel syndrome (IBS) is a functional gastrointestinal disorder associated with abdominal pain, abdominal discomfort, and disordered defecation [1]. The number of people with IBS has increased recently, especially in developed countries [2]. The prevalence and incidence of IBS are $10 \%-15 \%$ and $1 \%$ - $2 \%$ per year in the general population, respectively [2]. IBS is one of the most common disorders in digestive medical care [3,4].

The mechanism of IBS remains unknown. However, it has been clarified that most of the reported disorders, like dysregulation of the nervous system, altered intestinal motility, and increased visceral sensitivity, result 
from dysregulation of the bidirectional communication between the gut with its enteric nervous system and the brain (the brain-gut axis) [5].

In Japan and China, we conducted comparative studies on lifestyles and IBS for nursing and medical school students who were busy and had a relatively high amount of stress related to their daily duties [6,7]. The diagnosis of IBS was based on Rome II criteria. The results of those studies showed that the prevalence of the IBS was $25.2 \%$ in males and $41.5 \%$ in females in Japan [6], and $26.6 \%$ in males and $33.6 \%$ in females in China [7]. In both countries, more females had IBS than males. In addition, relationships were shown between IBS and anxiety, depression, sleep disorders, skipping meals and irregular meal times. In females of both countries, the IBS group showed a frequency for the intake of vegetables that was lower than that of the non-IBS group. Based on these results, we focused attention on lifestyle, including the daily habits of students with IBS. Accordingly, this study was conducted in order to intervene in the daily lives of the subjects and assess the effect of the intervention on the improvement of the IBS symptoms.

Treatment methods for patients with IBS vary widely depending on the individual subject concerned, due to individual character, genetics and environment differences [8-14]. How matters related to IBS and its symptoms are perceived results in a considerable disparity in the treatment of IBS, since IBS is a representative disorder of the brain-gut axis [15].

On the other hand, self-monitoring has been widely understood as one of the self-health management methods like the recording of weight, steps, blood pressure, the number of cigarettes smoked, and so on, because it is an easy and economical method [16-21]. Even for IBS patients, self-monitoring has had wide spread attention due to this cost-saving benefit [22,23]. Some studies have already reported the effect of self-monitoring for IBS, but most of those studies were fundamentally based on medication, and the self-monitoring was supplementary [24-26]. Besides, self-monitoring was focused on the mental side of the patients in those studies. Accordingly, this study was conducted to verify the effect of lifestyle self-monitoring for the improvement of IBS.

\section{METHODS}

\subsection{Study Population}

A total of 116 female freshmen at nursing schools in Kyoto prefecture participated in this study. Among these 116 students, two classes (39 and 38 students) were randomly chosen as the two-month and four-month intervention groups. Another class (39 students) was assigned as a control group. Among the 116 students, a total of 111 students (control group; $n=36$, two-month interven- tion group; $\mathrm{n}=37$, four-month intervention group; $\mathrm{n}=$ 38) answered self-administered questionnaires (95.7\%) after writing informed consent. According to our eligibility criteria, males, subjects with no diagnosis of inflamematory bowel disease, and no data inadequacy, 103 students (control group; $\mathrm{n}=34$, two-month intervention group; $\mathrm{n}=34$, four-month intervention group; $\mathrm{n}=35$ ) aged 18- to 26-years-old (mean \pm SD: $18.6 \pm 1.3$ ) were considered ineligible (88.8\%).

Study participants were asked to sign an informed consent form before they participated in the study. This study was approved by the Ethical Board of Kyoto Prefectural University.

\subsection{Questionnaire Information}

In order to obtain a questionnaire suitable for our purpose, we combined well-known criteria with some original items. The self-recording questionnaire contained 65 items, with the following sections; bowel habits (15 items), QOL related to gastrointestinal symptoms (15 items), psychological factors (14 items), dietary habits and lifestyle (16 items), physical characteristics (4 items) and treatment for disease (1 item). The time required to complete the questionnaire was 10 minutes. After all of the subjects answered the questionnaires, the two intervention groups monitored their own lifestyles for two or four months. After the intervention, everyone answered the same questionnaire again.

\subsection{IB Definitions}

This was the primary outcome measure. Patients with IBS were diagnosed with Rome II criteria [27]. Subjects were classified into three subgroups as follows: Diarrhea-predominant IBS (IBS-D), constipation-predominant IBS (IBS-C), and alteration type IBS (IBS-A). We used a Japanese version of the Rome II modular questionnaire, including 15 items complied by Shinozaki et al. [28].

\subsection{QOL Definitions}

The QOL points related to gastrointestinal disorders were applied according to the Gastrointestinal Symptom Rating Scale (GSRS) criteria [29]. The QOL of the subjects was assessed in five subscales of symptoms, acid reflux, abdominal pains, dyspepsia, diarrhea and constipation. The points applied for each of the items was the average point of the symptoms; for acid reflux it was the average of heartburn and regurgitation, for abdominal pains it was the average of epigastralgia, hunger pains and nausea, for dyspepsia it was it was the average of borborygmus, the feeling of fullness, eructation and abdominal wind, for diarrhea it was the average of a multitude of bowel movements, loose bowel movements, and 
urgent bowel movements, for constipation it was the average of few bowel movements, hard bowel movements and the feeling of incomplete evacuation, and for QOL related to gastrointestinal symptoms, it was the average point of these five subscales of symptoms. In each subscale, the minimum score of 1 indicated that the symptom did not affect the QOL at all. The maximum score of 7 indicated that the symptom had a harmful influence on the QOL. We used a modified Japanese version of the GSRS, including 15 items complied by Hongo et al. [30].

\subsection{Psychological Factors}

The hospital anxiety and depression scale (HADS) [31] was employed, a scale proven to be reliable and valid when screening for mood disorders. HADS can be divided into a subscale for anxiety (HAD-A) and a subscale for depression (HAD-D). In either of the HAD subscales, a score above 10 indicates definite clinically significant anxiety or depression, respectively, up to a maximum score of 21 . Respectively, a score of more than 11 points is regarded as a definite type, a score between 8 and 10 is doubtful and a score of less than 7 points indicates no mood disorder.

\subsection{Contents of Intervention}

\subsubsection{Self-Monitoring}

Subjects in the intervention groups recorded their daily habits every day for two or four months, including the contents of breakfast (staple dish, main dish and side dish), their awakening time, bedtime, hours of sleep, frequency of bowel movements, and mood of the day.

\subsubsection{Group Work}

In order to enhance the effectiveness of the self-monitoring, a fifteen-minute group work session was conducted every week as one of the basic subjects of the nursing course. The members of the group work session were the same 3 or 4 students for the intervention period. Each student set a goal to improve her lifestyle every week and wrote some messages in the self-monitoring sheet for the other members. Some groups made a presentation about their goals. After one week, they circulated the sheet in the group and assessed each other. The assessment points were as follows; "Have you remembered your goal for this week?", "Have you made any efforts to accomplish that goal?", "How much action have you taken toward your goal?”.

Figure 1 shows a flow chart for the intervention. Each intervention group continued the cycle of self-monitoring and the group work activity for two or four months. On the other hand, the control group did not conduct selfmonitoring or group work activity.

\subsubsection{Statistical Analysis}

All statistical computations were performed using the statistical software SPSS Ver.18 for windows. Wilcoxon's signed-rank test or McNemar's test was used to compare values obtained before and after intervention in each group. The Kruskal-Wallis test was used for comparisons among the three groups. Intention-to-Treat (ITT) analyses were employed for all of the analyses. A two-sided p value of less than 0.05 ( $p<0.05$ ) was considered statistically significant.

\section{RESULTS}

\subsection{Characteristics of the Subjects (Table 1)}

There were no statistically significant differences in age, height, weight and BMI between the three groups.

\subsection{Prevalence of IBS (Figures 2 and 3 )}

There was an 11.8 point decrease in IBS prevalence in the two-month intervention group. Meanwhile, there was only an 8.9 point decrease in the control group and a 5.8 point decrease in the four-month intervention group. In regard to the IBS-C subgroups, there were decreases of 8.8 and 2.8 points in the two-month and four-month intervention groups, respectively, but no change in the control group.

\subsection{The Relationship between Psychological Factors and IBS (Figure 4)}

The anxiety scores decreased 1.1 points in the two-month intervention group ( $p=0.02)$ and 2.0 points in the fourmonth intervention group ( $\mathrm{p}<0.01$ ), although there was only a 0.2 point decrease in the control group.

\subsection{Sleep Time, Defecation Habits, Dietary Habits and Contents of Meals (Table 2)}

In the two-month intervention group, time of sleep became irregular after the intervention $(p=0.01)$, since the awakening time $(\mathrm{p}<0.01)$ and bedtime $(\mathrm{p}<0.01)$ became irregular after the intervention. In the four-month intervention group, the percentage of students using laxatives decreased 17.2 percentage points after the intervention ( $p=0.01)$, although there were just 8.8 point and 5.9 point decreases in the control group and the twomonth intervention group, respectively.

The percent of students taking meals regularly decreased after the intervention in the control group and the four-month intervention group. In both of the intervention groups, the percent of students having three dishes at breakfast increased after the intervention. On the other hand, students having three dishes at lunch decreased significantly after intervention in the four-month intervention group $(p=0.01)$. 


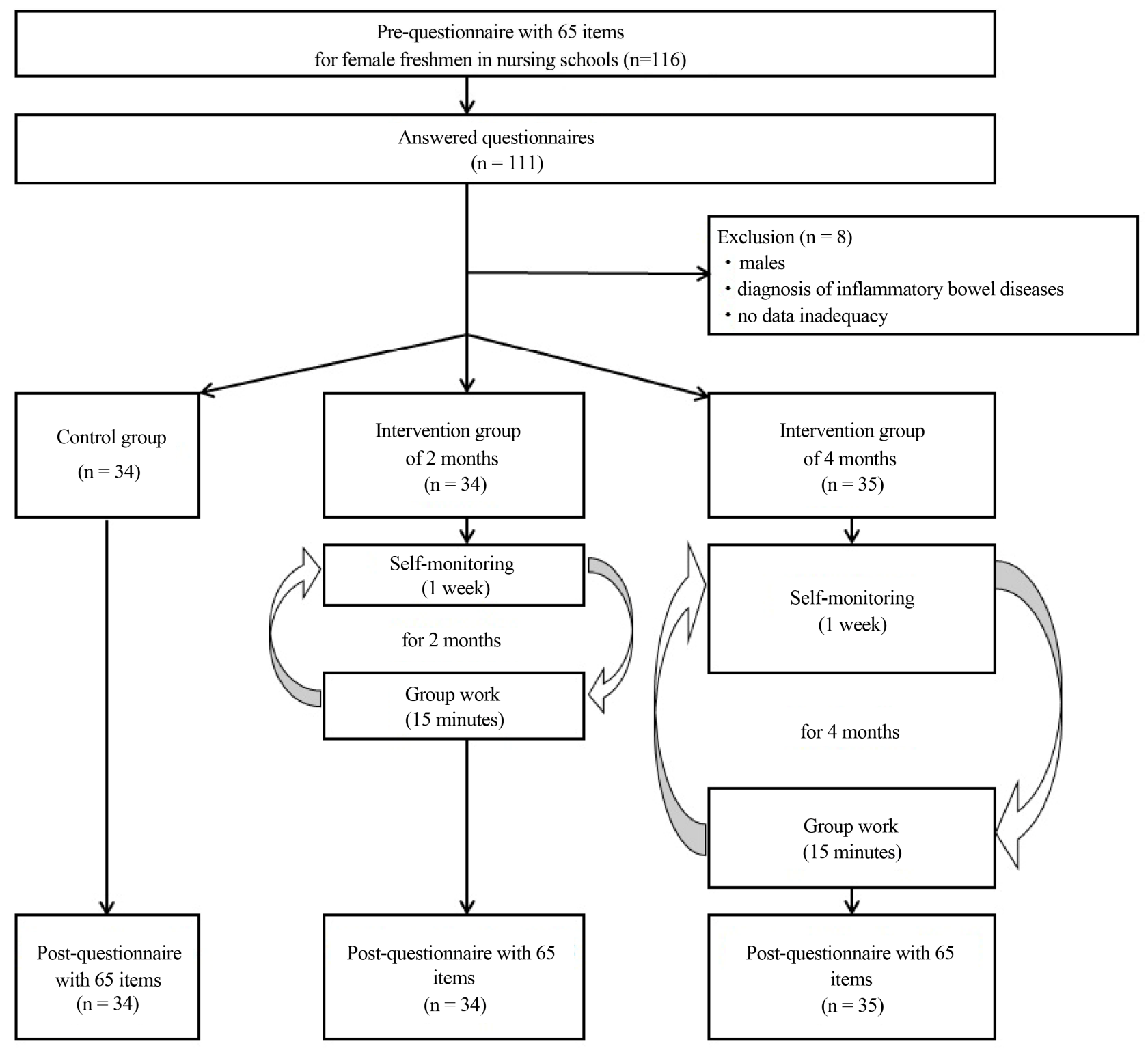

Figure 1. Flow chart of this study.

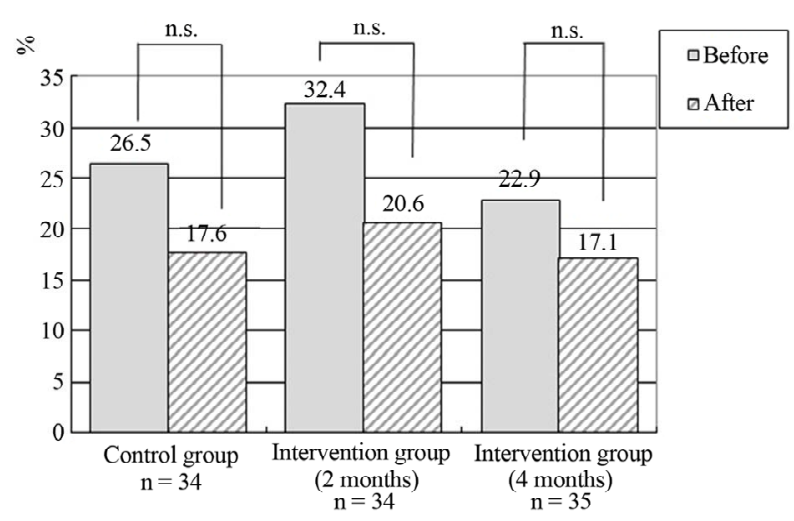

Figure 2. The prevalence of IBS in the intervention and the control groups IBS irritable bowel syndrome. n.s.: not significant. McNemar's test.
Table 1. Characteristics of the subjects in the intervention and the control groups.

\begin{tabular}{|c|c|c|c|c|}
\hline & $\begin{array}{l}\text { Control } \\
\text { group }\end{array}$ & $\begin{array}{l}\text { Intervention group } \\
\quad(2 \text { months })\end{array}$ & $\begin{array}{l}\text { Intervention group } \\
\quad(4 \text { months })\end{array}$ & $\mathrm{p}^{1}$ \\
\hline & $\mathrm{n}=34$ & $\mathrm{n}=34$ & $\mathrm{n}=35$ & \\
\hline Age & $18.3 \pm 0.6$ & $18.9 \pm 1.5$ & $18.5 \pm 1.5$ & 0.09 \\
\hline Height (cm) & $158.3 \pm 4.4$ & $158.7 \pm 6.4$ & $157.6 \pm 5.1$ & 0.72 \\
\hline Weight (kg) & $51.6 \pm 6.0$ & $50.6 \pm 5.7$ & $51.1 \pm 5.5$ & 0.79 \\
\hline BMI & $20.6 \pm 2.5$ & $20.3 \pm 1.9$ & $20.6 \pm 2.3$ & 0.97 \\
\hline
\end{tabular}

BMI: weight (kg)/height (m) ${ }^{2}$; ${ }^{1}$ Kruskal Wallis' test. 
Table 2. Sleep time, defecation habits, dietary habits and contents of meals in the intervention and the control groups.

\begin{tabular}{|c|c|c|c|c|c|c|c|c|c|c|c|c|c|c|c|}
\hline & \multicolumn{5}{|c|}{ Control group } & \multicolumn{5}{|c|}{ Intervention group (2 months) } & \multicolumn{5}{|c|}{ Intervention group (4 months) } \\
\hline & \multicolumn{2}{|c|}{ before } & \multicolumn{2}{|c|}{ after } & $\mathrm{p}^{1}$ & \multicolumn{2}{|c|}{ before } & \multicolumn{2}{|c|}{ after } & $\mathrm{p}^{1}$ & \multicolumn{2}{|c|}{ before } & \multicolumn{2}{|c|}{ after } & $\mathrm{p}^{1}$ \\
\hline & & $=34$ & & $=34$ & & & $=34$ & & $=34$ & & & $=35$ & & $=35$ & \\
\hline Awakening time & & & & & 0.69 & & & & & $0.01^{*}$ & & & & & 0.45 \\
\hline Regular & 27 & $(79.4)$ & 29 & (85.3) & & 32 & $(94.1)$ & 23 & $(67.6)$ & & 29 & $(82.9)$ & 26 & $(74.3)$ & \\
\hline Irregular & 7 & $(20.6)$ & 5 & $(14.7)$ & & 2 & (5.9) & 11 & $(32.4)$ & & 6 & $(17.1)$ & 9 & $(25.7)$ & \\
\hline Bedtime & & & & & 1.00 & & & & & $<0.01^{* *}$ & & & & & 0.58 \\
\hline Regular & 19 & (55.9) & 19 & (55.9) & & 25 & (73.5) & 16 & $(47.1)$ & & 18 & $(51.4)$ & 15 & $(42.9)$ & \\
\hline Irregular & 15 & $(44.1)$ & 15 & $(44.1)$ & & 9 & $(26.5)$ & 18 & (52.9) & & 17 & $(48.6)$ & 20 & $(57.1)$ & \\
\hline Time of sleep & & & & & 0.55 & & & & & $<0.01^{* *}$ & & & & & 0.55 \\
\hline Regular & 21 & $(61.8)$ & 18 & (52.9) & & 25 & (73.5) & 17 & $(50.0)$ & & 21 & $(60.0)$ & 18 & (51.4) & \\
\hline Irregular & 13 & $(38.2)$ & 16 & $(47.1)$ & & 9 & $(26.5)$ & 17 & $(50.0)$ & & 14 & $(40.0)$ & 17 & $(48.6)$ & \\
\hline Use of laxatives & & & & & 0.10 & & & & & 0.16 & & & & & $0.01^{*}$ \\
\hline Nothing & 26 & $(76.5)$ & 29 & (85.3) & & 29 & $(85.3)$ & 31 & $(91.2)$ & & 27 & $(77.1)$ & 33 & $(94.3)$ & \\
\hline Sometimes & 7 & (20.6) & 5 & (14.7) & & 5 & $(14.7)$ & 3 & (8.8) & & 7 & $(20.0)$ & 1 & (2.9) & \\
\hline Everyday & 1 & $(2.9)$ & 0 & $(0)$ & & 0 & $(0)$ & 0 & $(0)$ & & 1 & (2.9) & 1 & (2.9) & \\
\hline Time of meal & & & & & 0.16 & & & & & 0.16 & & & & & $0.01^{*}$ \\
\hline Regular & 11 & $(32.4)$ & 9 & (26.5) & & 7 & (20.6) & 7 & (20.6) & & 14 & $(40.0)$ & 8 & (22.9) & \\
\hline Sometimes irregular & 21 & $(61.8)$ & 21 & $(61.8)$ & & 23 & $(67.6)$ & 19 & (55.9) & & 16 & $(45.7)$ & 20 & $(57.1)$ & \\
\hline Irregular & 2 & $(5.9)$ & 4 & $(11.8)$ & & 4 & $(11.8)$ & 8 & (23.5) & & 5 & $(14.3)$ & 7 & $(20.0)$ & \\
\hline Contents of breakfast & & & & & 0.32 & & & & & 0.41 & & & & & 0.71 \\
\hline Three dishes & 1 & $(2.9)$ & 1 & (2.9) & & 6 & $(17.6)$ & 8 & $(23.5)$ & & 2 & $(5.7)$ & 3 & (8.6) & \\
\hline One or two dishes & 31 & $(91.2)$ & 32 & $(94.1)$ & & 27 & $(79.4)$ & 25 & $(73.5)$ & & 31 & $(88.6)$ & 28 & $(80.0)$ & \\
\hline No breakfast or only confectionaries & 2 & (5.9) & 1 & (2.9) & & 1 & $(2.9)$ & 1 & $(2.9)$ & & 2 & (5.7) & 4 & $(11.4)$ & \\
\hline Contents of lunch & & & & & 0.66 & & & & & 0.26 & & & & & $0.01^{*}$ \\
\hline Three dishes & 20 & $(58.8)$ & 20 & $(58.8)$ & & 17 & $(50.0)$ & 21 & $(61.8)$ & & 16 & $(45.7)$ & 8 & $(22.9)$ & \\
\hline One or two dishes & 14 & $(41.2)$ & 13 & $(38.2)$ & & 17 & $(50.0)$ & 12 & $(35.3)$ & & 19 & $(54.3)$ & 26 & $(74.3)$ & \\
\hline No lunch or only confectionaries & 0 & $(0)$ & 1 & (2.9) & & 0 & $(0)$ & 1 & (2.9) & & 0 & $(0)$ & 1 & (2.9) & \\
\hline Contents of dinner & & & & & 0.16 & & & & & 0.05 & & & & & 0.48 \\
\hline Three dishes & 22 & $(64.7)$ & 20 & $(58.8)$ & & 27 & $(79.4)$ & 23 & $(67.6)$ & & 21 & $(60.0)$ & 20 & $(57.1)$ & \\
\hline One or two dishes & 12 & $(35.3)$ & 14 & $(41.2)$ & & 7 & $(20.6)$ & 11 & $(32.4)$ & & 13 & $(37.1)$ & 13 & $(37.1)$ & \\
\hline No dinner or only confectionaries & 0 & $(0)$ & 0 & $(0)$ & & 0 & $(0)$ & 0 & (0) & & 1 & $(2.9)$ & 2 & $(5.7)$ & \\
\hline
\end{tabular}

${ }_{\mathrm{p}}^{*}<0.05,{ }^{* *} \mathrm{p}<0.01 ;{ }^{1}$ McNemar's test (for two categories) or Wilcoxon's signed-rank test (for three or more categories).

3.5. QOL Related to Gastrointestinal Symptoms (Table 3)

In the four-month intervention group, the QOL points related to all gastrointestinal disorders decreased after the intervention. Especially, the points for acid reflux ( $\mathrm{p}=$ $0.01)$, abdominal pains $(\mathrm{p}=0.01)$ and dyspepsia $(\mathrm{p}<$ 0.01 ) decreased significantly after the intervention. Due to these subscales, the average points decreased 0.3 points $(p<0.01)$ in the four-month intervention group. 
Table 3. QOL related to gastrointestinal symptoms in the intervention and the control groups.

\begin{tabular}{|c|c|c|c|c|c|c|c|c|c|}
\hline & \multicolumn{3}{|c|}{ Control group } & \multicolumn{3}{|c|}{ Intervention group (2 months) } & \multicolumn{3}{|c|}{ Intervention group (4 months) } \\
\hline & before & after & $\mathrm{p}^{1}$ & before & after & $\mathrm{p}^{1}$ & before & after & $\mathrm{p}^{1}$ \\
\hline & $\mathrm{n}=34$ & $\mathrm{n}=34$ & & $\mathrm{n}=34$ & $\mathrm{n}=34$ & & $\mathrm{n}=35$ & $\mathrm{n}=35$ & \\
\hline Reflux of acid & $1.4 \pm 0.7$ & $1.2 \pm 0.4$ & 0.08 & $1.3 \pm 0.5$ & $1.3 \pm 0.6$ & 0.72 & $1.6 \pm 0.7$ & $1.3 \pm 0.6$ & $0.01^{*}$ \\
\hline Abdominal pains & $1.7 \pm 1.0$ & $1.6 \pm 0.7$ & 0.41 & $1.6 \pm 0.8$ & $1.7 \pm 0.8$ & 0.83 & $2.0 \pm 0.9$ & $1.6 \pm 0.7$ & $0.01^{*}$ \\
\hline Dyspepsia & $1.9 \pm 0.8$ & $1.8 \pm 0.6$ & 0.27 & $2.2 \pm 1.1$ & $2.1 \pm 0.9$ & 0.27 & $2.1 \pm 0.8$ & $1.7 \pm 0.6$ & $<0.01^{* *}$ \\
\hline Diarrhea & $1.8 \pm 1.1$ & $1.6 \pm 1.0$ & 0.10 & $1.7 \pm 1.0$ & $1.7 \pm 0.8$ & 0.34 & $1.9 \pm 1.3$ & $1.7 \pm 1.1$ & 0.21 \\
\hline Constipation & $2.0 \pm 1.1$ & $1.9 \pm 1.1$ & 0.39 & $2.0 \pm 1.1$ & $2.1 \pm 1.2$ & 0.83 & $2.2 \pm 1.2$ & $2.1 \pm 1.1$ & 0.59 \\
\hline QOL related to gaestrinintestinal symptoms & $1.8 \pm 0.7$ & $1.6 \pm 0.5$ & 0.05 & $1.8 \pm 0.6$ & $1.8 \pm 0.6$ & 0.84 & $2.0 \pm 0.7$ & $1.7 \pm 0.7$ & $<0.01^{* *}$ \\
\hline \multicolumn{10}{|c|}{ Data are presented as mean $\pm \mathrm{SD}$} \\
\hline
\end{tabular}

${ }_{\mathrm{p}}^{*}<0.05,{ }^{* *} \mathrm{p}<0.01 ;{ }^{1}$ Wilcoxon's signed-rank test.

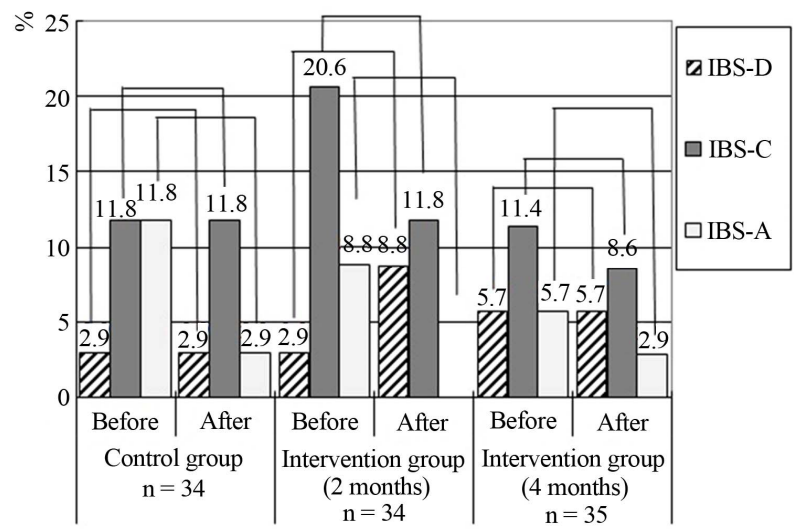

Figure 3. The prevalence of IBS subgroups in the intervention and the control groups IBS-D diarrhea predominant IBS, IBS-C constipation predominant IBS, IBS-A alteration type IBS. All comparisons were n.s. (not significant). McNemar’s test.

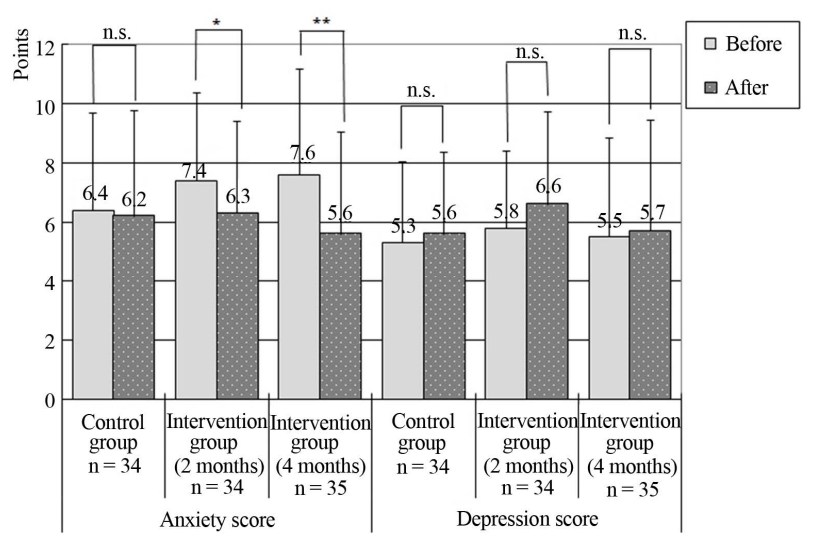

Figure 4. Anxiety and depression scores in the intervention and the control groups. Bars and lines are presented as mean and SD respectively. ${ }^{*} \mathrm{p}=0.02,{ }^{* *} \mathrm{p}<0.01$; n.s.: not significant. Wilcoxon's signed-rank test.

\section{DISCUSSION}

The characteristics of this study were as follows. First, this study was a school-based study, and not only students with IBS, but also ones without IBS participated in the study. Furthermore, the contents of intervention were self-monitoring and group work activities focused on lifestyle. Some studies [32-35] investigated the effects of self-monitoring focused on the emotions and feelings of the subjects, but we intervened in the lifestyles of the subjects using the self-monitoring method because we revealed a relationship between disordered lifestyles and IBS in our previous studies [6,7]. This study was the first to investigate the effects of lifestyle self-monitoring on the symptoms of IBS. In addition, we observed not only changes in the symptoms and QOL, but also changes in the lifestyles of the subjects after the intervention.

In this study, the prevalence of IBS decreased after the intervention in all groups, but there was no statistically significant difference between the intervention groups and the control group. Especially, the prevalence of the IBS-C subgroup decreased after the intervention in both of the intervention groups, but not in the control group.

In regard to the psychological factors, the anxiety scores decreased significantly in both of the intervention groups. This result showed the effectiveness of selfmonitoring and group work for the relief of anxiety. Sugaya et al. [35] reported that severe anxiety sensitivity in individuals with IBS was related to their symptomrelated cognition, and the altered cognition increased anxiety. We assume that anxiety comes from their cognitions and the way of thinking of themselves.

In regard to lifestyle, the meal, sleep, and defecation times became more irregular after the intervention in all of the groups. The reason for this might be because this 
study was conducted with first-year college students as the subjects. When the subjects were high school students, they regularly spent time studying for their college entrance examinations, but their lifestyles changed after entering college. At college, they can choose the classes they take by themselves, and most of the subjects worked part-time after classes. Their meal, sleeping, and defecation times tended to be very irregular along with these changes in lifestyle. The number of students who took three dishes at lunch decreased significantly after the intervention in the four-month intervention group. The number of students who took three dishes at dinner also decreased after the intervention in all of the groups. The reason for this is because most of the students started to live alone and cook by themselves. On the other hand, the contents of breakfast improved after the intervention in both of the intervention groups. This means that they recognized the importance of breakfast and were more aware of that importance due to the self-monitoring and the group work activities. The frequency of using laxatives decreased significantly in the four-month intervention group.

The QOL points related to gastrointestinal symptoms decreased 0.4 points after the intervention in the fourmonth intervention group. This depended on three items, acid reflux, abdominal pain and dyspepsia.

Previous studies [33,34] conducted psychoeducation for patients with IBS, showing a direct effect on global IBS symptom improvement and improvement in QOL, independent of its effects on distress [34]. In our study, there was an improvement of QOL related to gastrointestinal symptoms, but not any significant reduction of the IBS prevalence. Moss-Morris et al. [36] showed that symptomatic relief due to self-management was observed after an intervention and that the relief continued until six months later. They also reported that a clinically significant change in the IBS severance score was observed six months later. Kennedy et al. [24] also reported that the effect of cognitive behavioral therapy in addition to the intake of mebeverine continued until six month later. These studies showed the possibility that the effects of self-management continued for a while after the intervention or that it became visible some months after the intervention.

This study was limited for the following reasons. First, the persons who conducted this study were not specialists in self-monitoring. Second, we didn't compare selfmonitoring with other therapeutic approaches in this study. Third, the subjects of this study also included students who did not have any IBS symptoms. As a whole, there were only 28 students identified with IBS versus 75 students without before intervention. The more severe symptoms of IBS are, the more rapidly the effects of improvement surface [37]. Considering the fact, it was difficult to obtain a rapid response to the self-monitoring in this school-based study. Forth, we didn't follow up on the subjects until some time after the intervention. And lastly, this study was conducted with first-grade college students as the subjects in spring. The intervention period was during a time when the lifestyle of students underwent a lot of changes.

This study might be regarded as an exploratory research since the number of subjects was adjusted according to the number of classes and there were several primary outcome measures (Rome II, HADS and GSRS). These limitations must be considered in our future research. Future research should also include long-term follow-up studies of IBS patients treated with self-monitoring, and it might be more appropriate if the subjects were second or third year students.

Overall, this study showed that lifestyle self-monitoring intervention for two or four months didn't reduce the prevalence of the IBS significantly, but related to gastrointestinal symptoms, it did decrease anxiety and improved QOL.

\section{ACKNOWLEDGEMENTS}

We would like to express our thanks to the staff and all of the students that collaborated in this research at the Kyoto Prefectural University of Medicine and the nursing school at the Japan Red Cross Kyoto Daiichi Hospital.

\section{REFERENCES}

[1] Fujii, Y. and Nomura, S. (2006) The effects of psychosocial factors and daily habits of irritable bowel syndrome carriers on the symptoms and disease-specific QOL. Shokaki Shinshin Igaku, 13, 14-25.

[2] Talley, N.J. (1999) Irritable bowel syndrome: definition, diagnosis and epidemiology. Best Practice \& Research Clinical Gastroenterology, 13, 371-384. http://dx.doi.org/10.1053/bega.1999.0033

[3] Russo, M.W., Gaynes, B.N. and Drossman, D.A. (1999) A national survey of practice patterns of gastroenterologists with comparison to the past two decades. Journal of Clinical Gastroenterology, 29, 339-343. http://dx.doi.org/10.1097/00004836-199912000-00009

[4] Thompson, W.G., Heaton, K.W., Smyth, G.T., et al. (2000) Irritable bowel syndrome in general practice: prevalence, characteristics, and referral. Gut, 46, 78-82. http://dx.doi.org/10.1136/gut.46.1.78

[5] Fukudo, S., Nomura, T. and Hongo, M. (1998) Impact of corticotropin-releasing hormone on gastrointestinal motility and adrenocorticotropic hormone in normal controls and patients with irritable bowel syndrome. Gut, 42, 845849. http://dx.doi.org/10.1136/gut.42.6.845

[6] Okami, Y., Kato, T., Nin, G., et al. (2011) Lifestyle and psychological factors related to irritable bowel syndrome in nursing and medical school students. Journal of Gas- 
troenterology, 46, 1403-1410. http://dx.doi.org/10.1007/s00535-011-0454-2

[7] Okami, Y., Nin, G., Harada, K., et al. (2013) Irritable bowel syndrome in Chinese nursing and medical school students-Related lifestyle and psychological factors. Open Journal of Gastroenterology, 3, 55-63.

http://dx.doi.org/10.4236/ojgas.2013.31009

[8] Chang, L., Toner, B.B., Fukudo, S., et al. (2006) Gender, age, society, culture, and the patient's perspective in the functional gastrointestinal disorders. Gastroenterology, 130, 1435-1446.

http://dx.doi.org/10.1053/j.gastro.2005.09.071

[9] Faresjö, A., Anastasiou, F., Lionis, C., et al. (2006) Health-related quality of life of irritable bowel syndrome patients in different cultural settings. Health and Quality of Life Outcomes, 4, 21. http://dx.doi.org/10.1186/1477-7525-4-21

[10] Farnam, A., Somi, M.H., Sarami, F., et al. (2007) Personality factors and profiles in variants of irritable bowel syndrome. World Journal of Gastroenterology, 13, 64146418. http://dx.doi.org/10.3748/wjg.13.6414

[11] Handa, M., Nukina, H., Hosoi, M., et al. (2008) Childhood physical abuse in outpatients with psychosomatic symptoms. BioPsychoSocial Medicine, 2, 8. http://dx.doi.org/10.3748/wjg.13.6414

[12] Bengtson, M.B., Rønning, T., Vatn, M.H., et al. (2006) Irritable bowel syndrome in twins: Genes and environment. Gut, 55, 1754-1759.

http://dx.doi.org/10.1136/gut.2006.097287

[13] Saito, Y.A., Zimmerman, J.M., Harmsen, W.S., et al. (2008) Irritable bowel syndrome aggregates strongly in families: a family-based case-control study. Neurogastroenterology \& Motility, 20, 790-797. http://dx.doi.org/10.1111/j.1365-2982.2007.01077.x

[14] Ali, A., Toner, B.B., Stuckless, N., et al. (2000) Emotional abuse, self-blame, and self-silencing in women with irritable bowel syndrome. Psychosomatic Medicine, 62, 76-82.

[15] Drossman, D.A., Richter, J.E., Talley, N.J., et al. (1994) Functional gastrointestinal disorders. Little, Brown and Co., Boston, pp. 1-174.

[16] Kamaura, M., Ohono, H., Takahashi, M., et al. (2007) Evaluation of a guidance method for reducing lifestylerelated diseases by the self-monitoring of blood collection in small- and medium-sized enterprises. Sangyo Eiseigaku Zassh., 49, 89-97.

http://dx.doi.org/10.1539/sangyoeisei.49.89

[17] Aittasalo, M., Miilunpalo, S., Kukkonen-Harjula, K., et al. (2006) A randomized intervention of physical activity promotion and patient self-monitoring in primary health care. Preventive Medicine, 42, 40-46. http://dx.doi.org/10.1016/j.ypmed.2005.10.003

[18] Halme, L., Vesalainen, R., Kaaja, M., et al. (2005) Self-monitoring of blood pressure promotes achievement of blood pressure target in primary health care. American Journal of Hypertension, 18, 1415-1420. http://dx.doi.org/10.1016/j.amjhyper.2005.05.017

[19] Soumerai, S.B., Mah, C., Zhang, F., et al. (2004) Effects of health maintenance organization coverage of selfmonitoring devices on diabetes self-care and glycemic control. Archives of Internal Medicine, 164, 645-652. http://dx.doi.org/10.1001/archinte.164.6.645

[20] Mossavar-Rahmani, Y., Henry, H., Rodabough, R., et al. (2004) Additional self-monitoring tools in the dietary modification component of The Women's Health Initiative. Journal of the American Dietetic Association, 104, 76-85. http://dx.doi.org/10.1016/j.jada.2003.10.017

[21] Sjöberg, S., Carlson, A., Rosenqvist, U., et al. (1988) Health attitudes, self-monitoring of blood glucose, metabolic control and residual insulin secretion in type 1 diabetic patients. Diabetic Medicine, 5, 449-453.

http://dx.doi.org/10.1111/j.1464-5491.1988.tb01026.x

[22] Andersson, E., Ljótsson, B., Smit, F., et al. (2011) Costeffectiveness of internet-based cognitive behavior therapy for irritable bowel syndrome: Results from a randomized controlled trial. BMC Public Health, 11, 215. http://dx.doi.org/10.1186/1471-2458-11-215

[23] Everitt, H.A., Moss-Morris, R.E., Sibelli, A., et al. (2010) Management of irritable bowel syndrome in primary care: Feasibility randomised controlled trial of mebeverine, methylcellulose, placebo and a patient self-management cognitive behavioural therapy website. (MIBS trial). BMC Gastroenterology, 10, 136. http://dx.doi.org/10.1186/1471-230X-10-136

[24] Kennedy, T.M., Chalder, T., McCrone, P., et al. (2006) Cognitive behavioural therapy in addition to antispasmodic therapy for irritable bowel syndrome in primary care: Randomised controlled trial. Health Technology Assessment, 10, 1-67.

[25] Mahvi-Shirazi, M., Fathi-Ashtiani, A., Rasoolzade-Tabatabaei, S.K., et al. (2012) Irritable bowel syndrome treatment: cognitive behavioral therapy versus medical treatment. Archives of Medical Science, 8, 123-129. http://dx.doi.org/10.5114/aoms.2012.27292

[26] Reme, S.E., Stahl, D., Kennedy, T., et al. (2011) Mediators of change in cognitive behaviour therapy and mebeverine for irritable bowel syndrome. Psychological Medicine, 41, 2669-2679. http://dx.doi.org/10.1017/S0033291711000328

[27] Thompson, W.G., Longstreth, G.F., Drossman, D.A., et al. (1999) Functional bowel disorders and functional abdominal pain. Gut, 45, 43-47.

[28] Shinozaki, M., Kanazawa, M., Sagami, Y., et al. (2006) Validation of the Japanese version of the Rome II modular questionnaire and irritable bowel syndrome severity index. Journal of Gastroenterology, 41, 491-494. http://dx.doi.org/10.1007/s00535-006-1799-9

[29] Dimenäs, E., Glise, H., Hallerbäck, B., et al. (1995) Well-being and gastrointestinal symptoms among patients referred to endoscopy owing to suspected duodenal ulcer. Scandinavian Journal of Gastroenterology, 30, 10461052. http://dx.doi.org/10.3109/00365529509101605

[30] Hongo, M., Fukuhara, S. and Joseph, G. (1999) Evaluation of Japanese gastrointestinal symptom rating scale. Diagnosis and Treatment, 87, 731-736.

[31] Hatta, H., Higashi, A., Yashiro, H., et al. (1998) A vali- 
dation of the hospital anxiety and depression scale. Japanese Journal of Psychosomatic Medicine, 38, 309315.

[32] Gros, D.F., Antony, M.M., McCabe, R.E., et al. (2011) A preliminary investigation of the effects of cognitive behavioral therapy for panic disorder on gastrointestinal distress in patients with comorbid panic disorder and irritable bowel syndrome. Depression and Anxiety, 28, 10271033. http://dx.doi.org/10.1002/da.20863

[33] Lackner, J.M., Jaccard, J., Krasner, S.S., et al. (2007) How does cognitive behavior therapy for irritable bowel syndrome work? A mediational analysis of a randomized clinical trial. Gastroenterology, 133, 433-444. http://dx.doi.org/10.1053/j.gastro.2007.05.014

[34] Lackner, J.M., Jaccard, J., Krasner, S.S., et al. (2008) Self-administered cognitive behavior therapy for moderate to severe irritable bowel syndrome: Clinical efficacy, tolerability, feasibility. Clinical Gastroenterology and Hepatology, 6, 899-906. http://dx.doi.org/10.1016/j.cgh.2008.03.004

[35] Sugaya, N., Nomura, S. and Shimada, H. (2012) Relationship between cognitive factors and anxiety in individuals with irritable bowel syndrome. International Journal of Behavioral Medicine, 19, 308-315. http://dx.doi.org/10.1007/s12529-011-9195-0

[36] Moss-Morris, R., McAlpine, L., Didsbury, L.P., et al. (2010) A randomized controlled trial of a cognitive behavioural therapy-based self-management intervention for irritable bowel syndrome in primary care. Psychological Medicine, 40, 85-94. http://dx.doi.org/10.1017/S0033291709990195

[37] Lackner, J.M., Gudleski, G.D., Keefer, L., et al. (2010) Rapid response to cognitive behavior therapy predicts treatment outcome in patients with irritable bowel syndrome. Clinical Gastroenterology and Hepatology, 8, 426-432. http://dx.doi.org/10.1016/j.cgh.2010.02.007

\section{ABBREVIATIONS}

BMI, body mass index;

HADS, the hospital anxiety and depression scale;

HAD-A, a subscale for anxiety;

HAD-D, a subscale for depression;

GSRS, the Gastrointestinal Symptom Rating Scale;

QOL, quality of life; IBS, irritable bowel syndrome;

IBS-A, the alteration type IBS;

IBS-C, the constipation-predominant IBS;

IBS-D, the diarrhea-predominant IBS;

SD, standard deviation. 